\title{
Association between societal costs and treatment response in children and adolescents with ADHD and their parents. A cross-sectional study in the Netherlands
}

Annemarie van der Kolk ${ }^{1,2 *}$, Clazien AM Bouwmans ${ }^{3}$, Saskia J Schawo ${ }^{3}$, Jan K Buitelaar ${ }^{1,4}$, Michel van Agthoven ${ }^{5}$ and Leona Hakkaart-van Roijen ${ }^{3}$

\begin{abstract}
Attention Deficit Hyperactivity Disorder (ADHD) is associated with considerable burden of illness at a patient, family and societal level. Although pharmacological treatment is recommended by authoritative guidelines, evidence on its influence on the broader burden of illness is limited. As treatment induces costs, proper healthcare decision making requires evidence on the associated societal costs or benefits and particularly the difference that response to treatment can make.

Data on ADHD related resource use of patients 8-18 years and parents were collected by means of a cross-sectional, online survey amongst members of the Dutch parent association. Children were stratified to responders and non-responders to treatment according to pre-defined expert definitions.

Analyses were performed on 618 questionnaires (428 responders; 190 non-responders to treatment). Children were 11.8 years on average and mainly boys ( $82 \%$ ). Total monthly costs for children were $€ 578$ and $€ 839$ for responders and non-responders, respectively $(p=0.021)$, with a breakdown to direct medical costs ( $€ 322$ vs. $€ 512 ; p=0.068)$, direct non-medical costs ( $€ 222$ vs. $€ 296 ; p=0.090$ ), and indirect non-medical costs ( $€ 34$ vs. $€ 57 ; p<0.001)$. For parents, total costs were $€ 246$ vs. $€ 399$ for the responding and non-responding children, respectively $(p=0.006)$, with a breakdown to direct medical costs ( $€ 130$ vs. $€ 211 ; p=0.010)$ and indirect non-medical costs ( $€ 116$ vs. $€ 181 ; p=0.092)$. Total monthly costs of children and their parents together were $€ 824$ and $€ 1228$ for responders and non-responders to treatment, respectively $(p=0.002)$.

These results stress the importance of a focus on response to treatment, not only beneficial for patients and their family, but also resulting in considerable societal benefits.
\end{abstract}

Keywords: ADHD; Societal costs; Burden of illness; Treatment response; Cross-sectional

\section{Introduction}

Attention Deficit Hyperactivity Disorder (ADHD) is a heterogeneous psychiatric disorder characterized by a chronic pattern of age-inappropriate inattention, hyperactivity and impulsivity with a worldwide-pooled prevalence of 5.3 \% (Asherson 2004; Polanczyk et al. 2007;

\footnotetext{
* Correspondence: avdkolk@its.jnj.com

${ }^{1}$ Radboud University Medical Centre, Donders Institute for Brain, Cognition and Behavior, Department of Cognitive Neuroscience, P.O. Box 9010, 6500, $\mathrm{GL}$, Nijmegen, the Netherlands

2Janssen-Cilag BV, P.O. Box 90240, 5000, LT, Tilburg, the Netherlands Full list of author information is available at the end of the article
}

Swanson et al. 2009). Adverse consequences of ADHD may be far-reaching and symptoms often persist into adulthood (Barkley 2008; Coghill et al. 2008; Faraone et al. 2006; Michielsen et al. 2012).

ADHD is associated with a considerable burden of illness at both the patient, family, and societal level (Birnbaum et al. 2005; Doshi et al. 2012; Erskine et al. 2014; Le et al. 2013). Several studies concluded that ADHD has a negative impact on family, school and environmental level reflected in a lower quality of life (QoL), increased use of healthcare resources and risk for injuries, substance abuse, delinquency, and driving violations 
(Danckaerts et al. 2009; De Ridder \& De Graeve 2006; Hakkaart-van Roijen et al. 2007; Mannuzza et al. 2008; Thompson et al. 2007; van den Ban et al. 2014; van der Kolk et al. 2014). The influence of ADHD on others than the patient is previously shown by productivity losses of parents and an increased use of healthcare resources by family members (Birnbaum et al. 2005; Swensen et al. 2003). Treatment by medication has been shown to decrease ADHD symptoms and to consequently improve the level of functioning. Medication is recommended by authoritative treatment guidelines worldwide as a first-line treatment option in case of ADHD (Banaschewski et al. 2006; Canadian Attention Deficit Hyperactivity Disorder Resource Alliance 2010; National Institute for Health and Clinical Excellence 2006; Trimbos-instituut et al. 2005; Wolraich et al. 2011). A recent systematic review of longterm outcomes of ADHD treatment and non-treatment supports the premise that without accurate treatment, people with ADHD experience poorer long-term outcomes (Shaw et al. 2012). Also, non-adherence to treatment could jeopardize treatment outcome (van den Ban et al. 2010). However, evidence is limited regarding the influence of treatment by medication on health care resource use of ADHD patients and their families, and the associated economic burden. This is a hindrance for the evaluation of the cost-effectiveness of current and future pharmacological interventions for ADHD (Le et al. 2013).

Studies on health care resource use and costs are preferably conducted from the societal point of view (Jonsson 2009). A profound societal analysis includes medical (inside the health care sector) and non-medical costs (outside the health care sector), both direct (e.g. a visit to a doctor) and indirect costs (e.g. absence from work due to illness) (Jonsson 2009). This broad societal perspective is especially indicated in evaluating the economic burden of chronic diseases like Alzheimer's disease, Multiple Sclerosis, Rheumatoid Arthritis and ADHD. These are all examples of disease areas where new innovations could lead to reductions in costs for society due to reductions in productivity gains and reductions in costs for community and informal care (Jonsson 2009). However, only few studies have monetized the impact of ADHD systematically by providing an impression of the overall impact of ADHD from a societal perspective with a comprehensive measurement of indirect costs (Doshi et al. 2012; Le et al. 2013). A recent review concluded that data is lacking to draw conclusions regarding the relative cost-effectiveness of different pharmacological agents in ADHD (Le et al. 2013). In recent years, the issue of non-compliance with (pharmacological) treatment is studied further to evaluate the clinical and economic effects of the management of compliance in patients (Hiligsmann et al. 2012). In ADHD treatment, persistence to treatment is frequently suboptimal indicating impaired compliance (van den Ban et al. 2010). Poor compliance, or in broader terms poor response to treatment, reduces the potential benefits from therapy. To our knowledge, costs in children with ADHD have not been studied in association to response to treatment.

This paper therefore presents a cost study on ADHD from the societal perspective including costs related to resource use and productivity losses. As medication is recommended by guidelines as a first-line treatment option and response to treatment is associated with potential treatment benefit, proper healthcare decision making requires evidence on the associated societal costs or benefits and particularly the difference response to treatment can make.

\section{Methodology}

The present study was part of a larger study on the burden of ADHD from a societal perspective including QoL (van der Kolk et al. 2014). The current study analyses all direct and non-medical indirect costs related to ADHD (Table 1). Data on healthcare consumption of children and their parents and productivity losses of parents were collected by means of a cross-sectional, online survey that was completed by parents.

\section{Study sample}

The study sample was derived out of the members of the Dutch association Balans for parents of children with developmental disorders (amongst others, but not limited to

Table 1 Types of resource use included for children $\left(\mathrm{Ch}^{\mathrm{a}}\right)$ and parents $\left(P^{b}\right)$ or both groups $(C h-P)$

\begin{tabular}{lll}
\hline & Direct & Indirect \\
\hline Medical & Medical consultations (Ch-P) & d \\
& Skills training (Ch) & \\
& Parent training (P) & \\
& Day-care treatment (Ch) & \\
& Hospitalization (Ch) & \\
& Medication (Ch-P) & \\
Non-medical & Remedial teaching at & Agency for child \\
& school (Ch) & welfare (Ch) \\
& Weekend care (Ch) & Police (Ch) \\
& Care after school (Ch) & Special education (Ch) \\
& Diet (Ch) & Productivity losses \\
& & Absenteeism (P) \\
& & Presenteeism (P) \\
\hline
\end{tabular}

${ }^{\mathrm{a}} \mathrm{Ch}$ : Item included in the cost calculation of the children only

${ }^{b}$ : Item included in the costs for parents referred to their own health consumption because of their child's ADHD

'Ch\&P: Item included in both the cost calculation for the children as well as in the cost calculation for the parents, but costs for children are not included in the costs for parents

dIndirect medical costs are excluded according to the Dutch guidelines for pharma-economic research (College voor zorgverzekeringen afdeling pakket 2006) 
ADHD, Asperger's syndrome, Dyslexia, oppositional defiant disorder (ODD), and conduct disorder (CD)). Parents of children with ADHD were asked via the magazine of the association to join the study online by means of a personal login code. Inclusion criterion: being a parent of a child aged 8-18 years diagnosed with ADHD. Because of this membership, it was assumed valid to rely on the parents' knowledge about the ADHD diagnosis of their child. Due to anonymity it was not possible to verify whether the diagnosis was indeed valid.

The questionnaire was available from 01-09-2010 until 03-10-2010. The parent taking care of the child most of the day was asked to complete the questionnaire. Parents were not reimbursed for their participation in any way. In case the parent had more than one child with ADHD, parents were asked to answer the questions for their youngest child. Since the study did not interfere with clinical practice, according to Dutch regulation no approval of an ethics committee was needed. Also, with the methodology of this study focusing on parents instead of patients, it was not obligatory to use informed consent forms. Nevertheless, the protocol took into account all privacy aspects and all necessary efforts were taken in this study to protect privacy. Participants were informed on the purpose of data collection (scientific publication), respondents were fully free to decide to join and were able to exit the questionnaire at any time. Due to the login code that was distributed by Balans magazine, only members of Balans were able to access the questionnaire. The questionnaire could be completed only once per IP address, but these IP addresses were not saved and/or traceable so participants' anonymity was guaranteed. Also, adequate security measures were employed in order to prevent unauthorized access, manipulation to or disclosure of the personal data although these were already unidentifiable when stored.

\section{Responder groups}

In order to investigate the association between costs and response to treatment, descriptions for response to treatment had to be defined since these were not readily available. These descriptions were created by five Dutch ADHD experts. This number of five experts was considered appropriate for the study, in accordance with minimum requirements of a Delphi panel (Evans \& Crawford 2000). The panel of experts was selected based on their experience in the field of ADHD treatment, and a scientific focus. The experts included were child-and youth psychiatrists $(\mathrm{n}=5)$, both male $(\mathrm{n}=4)$ and female $(\mathrm{n}=1)$ and aged 43 to 55 (mean 49.8). The experts had 10 to 22 years of experience with ADHD medication and treated 30-90 ADHD patients per month. The experts were consulted independently and were not aware of the identity of the other experts joining the panel. An expert not joining the Delphi panel verified the questions proposed to the experts in advance. The questions for the panel were sent and returned by email. After all experts had returned the questionnaires, their answers were combined. The proposals for the final answers, as well as the anonymous individual answers of the participants were reported to the experts after round 1 . In the second round, experts were asked whether they liked to change their previous answers, based on the proposal for the final answer. Before distributing the questions to the experts, it was decided that consensus was supposed to be reached after two rounds of answers when (a) feedback of the experts was clear and (b) when experts did not all change their answers based on the mean of the feedback of the first round. The experts indicated that two assumptions were crucial for the foundation of the definitions for response to treatment and non-response to treatment. First, based on an earlier study, response to medication had to be defined by recovery both at home and at school in order to reflect a proper description of the child's daily functioning (functioning - F) (Buitelaar et al. 1995; Hodgkins et al. 2013). Second, as compliance to medication is known to play an important role in the child's functioning, it was considered necessary to include a statement on the child's compliance as well (compliance - C) (Charach \& Fernandez 2013). Theoretically, this led to the following combinations:

- $\left(\mathrm{C}^{+} ; \mathrm{F}^{+}\right)$: Compliance to prescribed daily dose of medication, no problems in functioning.

- $\left(\mathrm{C}^{-} ; \mathrm{F}^{-}\right)$: Non-compliance to prescribed daily dose of medication, problems in functioning.

- $\left(\mathrm{C}^{-} ; \mathrm{F}^{+}\right)$: Non-compliance to prescribed daily dose of medication, no problems in functioning.

- $\left(\mathrm{C}^{+} ; \mathrm{F}^{-}\right)$: Compliance to prescribed daily dose of medication, problems in functioning.

The experts decided to exclude combinations $\left(\mathrm{C}^{-} ; \mathrm{F}^{+}\right)$ and $\left(\mathrm{C}^{+} ; \mathrm{F}^{-}\right)$. Experts considered $\left(\mathrm{C}^{-} ; \mathrm{F}^{+}\right)$to describe children not requiring medication, as no problems arise when medication is not taken according to prescription. $\left(\mathrm{C}^{+} ; \mathrm{F}^{-}\right)$was considered to reflect several situations in which proper compliance is not translated into proper functioning: inappropriate dosing, inappropriate medication, or presence of an undiagnosed but relevant comorbid condition. The design of the study precluded to analyze these situations. The two remaining combinations, $\left(\mathrm{C}^{+} ; \mathrm{F}^{+}\right)$ and $\left(\mathrm{C}^{-} ; \mathrm{F}^{-}\right)$, were the basis for responder group definition. As it was deemed necessary to provide parents with a hands-on description of these groups, the experts operationalized the combinations to the following descriptions based on treatment compliance and functioning in family, school and the environmental level:

- Responder to treatment: 'Your child uses the prescribed daily dose of medication. Using this 
treatment, your child's functioning is fine and there are no noteworthy problems at home, at school, with peers or during leisure time.'

- Non-responder to treatment: 'The daily dose of medication used by your child differs from the dose prescribed. Using this treatment, your child's functioning is quite fine, but he/she is hampered by problems at home, at school, with peers or during leisure time for short periods of time'.

\section{The questionnaire}

The questionnaire on healthcare consumption and productivity losses for patients with psychiatric disorders (TiC-P) was used, which is designed for self-report and is focused on psychiatric disorders like ADHD (van Roijen et al. 1996). Two versions are available, one for adults and one for adults to describe their children (Bouwmans et al. 2013b; Bouwmans \& Hakkaart-van Roijen 2013b). The selection of this questionnaire was based on feasibility, reliability and validity combined with comprehensiveness of cost items and ability of online use (Bouwmans et al. 2013a). The questionnaire had been used on an ADHD sample in another study before (Hakkaart-van Roijen et al. 2007). In the present study, both TiC-P versions were used. The questionnaire was adjusted using information from a previously performed study focused on societal cost related to ADHD as is allowed by the TiC-P manual (Bouwmans \& Hakkaart-van Roijen 2013a; Hakkaart-van Roijen et al. 2007). The recall period was one month for both medical consumption and productivity losses. TiC-P starts with general demographic questions on gender, age, (type of) education, marital status, and job.

TiC-P questionnaires are generic, meaning that items are not related to a specific disorder. In this study, resource use was supposed to be related to the 'target disorder' ADHD. Parents were provided with examples of costs that were either related (visiting a doctor for ADHD problems) or non-related to ADHD (visiting an ear, nose and throat specialist for ear tubes) to aid them in making a correct distinction. This could also mean costs for parents getting coaching and/or parenting tips; this is only necessary because of their child with ADHD and therefore these costs are considered related to ADHD. Costs for parents referred to their own health consumption only plus costs due to productivity losses.

Table 1 presents the cost items that were included, Table 2 presents the unit costs per cost item. For children, additional questions to Table 2 were focused on costs for diet, the use of ADHD medication, use of special education and absence from school or sports. Costs of productivity losses were focused on productivity losses of paid work including absenteeism (absence from work) and presenteeism (reduced productivity while at work).
Non-paid work was not included in this study, since parents of children aged 8-18 were expected to have limited voluntary activities.

\section{Cost calculation}

Bottom-up methodology was used to calculate total direct medical costs; that is, the total number of medical contacts was multiplied by the reference prices based on the Dutch manual for cost studies (prices were updated to 2012 prices) (Hakkaart-van Roijen et al. 2011). A visit to 'RIAGG' (Dutch mental health facility: a combination of $1^{\text {st }}$ and $2^{\text {nd }}$ line care) was assumed to have similar costs as $1^{\text {st }}$ line mental health care in case of ADHD. Unit costs for a visit to a school doctor and a company doctor were assumed to be similar to a general practitioner visit as costs for a school doctor and a company doctor were not defined in the costing manual. These assumptions were confirmed by a specialist in costing studies (LH). Costs for individual and group trainings were not specified in the costing manual. For individual sessions, costs for ambulatory $2^{\text {nd }}$ line care were assigned based on communication by the Dutch mental health association 'GGZ Nederland'. For group trainings, the association estimated time used by the expert divided by the number of clients per session. For day-care, a weighted average of day-care treatment ( $8 \mathrm{~h}$ a day) and half-time treatment ( $4 \mathrm{~h}$ a day) was used (day-treatment $€ 183.70+$ half-time treatment $€ 163.53)$. For parents, the average number of days of medication use in the entire group of parents per month was multiplied by mean public Dutch costs of medication use in adults ( $€ 0.66$ per day) (Stichting Farmaceutische Kengetallen 2012). Direct non-medical costs related to weekend care and care after school were based on several sources as these were not defined in the costing manual. Weekend care was estimated based on productivity costs (Hakkaart-van Roijen et al. 2011). For remedial teaching, average price per hour for remedial teaching were used for cost calculation (Landelijke beroepsvereniging remedial teachers 2014). Care after school was rated based on average costs for baby-sitting (Nibud 2013). For diets, parents were asked to define costs below $€ 25$, between $€ 25$ and $€ 50$ or above $€ 50$ in one month if a special diet was indicated. For indirect nonmedical costs, the agency for child welfare and police were assumed to have the same cost price since costs for police was not defined in the costing manual (Hakkaart-van Roijen et al. 2011). Prices for special education were based on prices of the Dutch Ministry of Education with a yearly additional cost of $€ 4700$ (Ministerie van Onderwijs 2012). This led to extra monthly costs for special primary and special secondary education of $€ 392$ compared to regular education. For the questions on child's health-related school absence and failure to participate in sports due to ADHD no costs were assigned. Cost of absence from work 
Table 2 Unit costs used for children (Ch) and parents (P) or both groups (Ch-P) in Euro 2012

\begin{tabular}{|c|c|c|}
\hline & Ch-P & Unit costs (Hakkaart-van Roijen et al. 2011) ${ }^{a}$ \\
\hline Consultation per session & - & - \\
\hline General Practitioner & Ch-P & 29.73 \\
\hline Psychologist $^{\mathrm{b}}$ & Ch-P & 84.95 \\
\hline Social worker & Ch-P & 69.02 \\
\hline Psychotherapist, first line ${ }^{c}$ & Ch-P & 81.76 \\
\hline $\mathrm{RIAGG}^{\mathrm{d}}$ & Ch-P & 81.76 \\
\hline Phychiatrist outpatients' department & $\mathrm{P}$ & 109.37 \\
\hline Medical specialist & $\mathrm{Ch}$ & 109.37 \\
\hline Emergency Room & $\mathrm{Ch}$ & 160.34 \\
\hline Physiotherapist & $\mathrm{Ch}$ & 38.23 \\
\hline Occupational therapist & $\mathrm{Ch}$ & 23.36 \\
\hline Speech therapist & $\mathrm{Ch}$ & 35.04 \\
\hline Alternative therapist & Ch-P & 50.00 (Nederlandse Orde van Alternatieve Genezers 2013) \\
\hline Paramedical (physiotherapist, occupational and alternative therapist) & $P$ & 37.12 \\
\hline School doctor & $\mathrm{Ch}$ & 29.73 \\
\hline Company doctor & $\mathrm{P}$ & 29.73 \\
\hline Trainings per session & - & - \\
\hline Social skills training/creative therapy/self regulation ${ }^{e}$ - individual & $\mathrm{Ch}$ & 181.58 \\
\hline Social skills training/creative therapy/self regulation ${ }^{e}$ - group & $\mathrm{Ch}$ & 100.00 \\
\hline Psychological education ${ }^{f} /$ parent training/family coach - individual & $\mathrm{P}$ & 181.58 \\
\hline Psychological education ${ }^{f} /$ parent training/family coach - group & $\mathrm{P}$ & 100.00 \\
\hline Day-care treatment & $\mathrm{Ch}$ & 173.62 \\
\hline Hospitalization & $\mathrm{Ch}$ & 246.35 \\
\hline Agency for child welfare & $\mathrm{Ch}$ & 69.02 \\
\hline Weekend care (hours) & $\mathrm{Ch}$ & 13.27 \\
\hline Police (contacts) & $\mathrm{Ch}$ & 69.02 \\
\hline Remedial teaching at school (hours) ${ }^{g}$ & $\mathrm{Ch}$ & 55.00 (Landelijke beroepsvereniging remedial teachers 2014) \\
\hline Care after-school (hours) & $\mathrm{Ch}$ & 5.93 (Nibud 2013) \\
\hline
\end{tabular}

${ }^{a}$ Dutch cost manual unless specified otherwise and prices were indexed to 2012 prices

${ }^{b}$ Second line care aimed at more severe complaints needing a longer treatment duration

'Short duration (up to 8 sessions) aimed at mild to moderate complaints

${ }^{\mathrm{d}}$ Regional institution for ambulant psychiatric health care

${ }^{\mathrm{e}}$ To control or direct oneself according to rule

fProvide information to parents regarding coping with the ADHD of their child

${ }^{9}$ Special teaching for backward and slow learners

of the parent related to their child with ADHD was calculated by multiplying the number of days off work with predefined productivity costs per hour of absence with a specification to age group and gender (Hakkaart-van Roijen et al. 2011). Costs of presenteeism was determined by the Osterhaus method (Osterhaus et al. 1992). Parents were asked about the number of days of hindrance due to ADHD of their child and their estimated efficiency on these days in comparison to usual efficiency. Linear extrapolation (LE) was applied as it was in a former ADHD study as well (Hakkaart-van Roijen et al. 2007). Applying LE, all costs were extrapolated to one year by multiplying the monthly costs by twelve assuming the monthly costs to reflect usual costs. There is no specific reason to assume that the cost distribution is non-linear, although there might be small variations during the year.

\section{Statistical analysis}

Completeness of the data is reported based on numbers completing the questionnaire. Furthermore, the data was reviewed for fraudulent responses, errors (intentional or not), missing data and possible strange patterns indicating programming errors. Study variables are described using absolute numbers (mean and median), percentages and $95 \%$ confidence intervals. Missing data was replaced by means of multiple imputation as is the recommended 
method to reflect estimates across the range of circumstances considered (Manca \& Palmer 2005). Variables were considered candidates for the imputation process based on simple regression followed by a regression model based on significance and their independent influence on total costs. To check if distribution was normal, data were tested for skewness. Descriptive statistics, independent samples $t$-test and Chi-square test were used accordingly for analyzing differences between groups $(\mathrm{p}<0.05$; 2-tailed). As healthcare cost data tend to be skewed, tests were repeated using Mann-Whitney tests to check if conclusions remained similar using a test for non-parametric data. Multiple regression analysis was used to check for independent influence of other factors than treatment response on the mean total costs. A p-value of $<0.05$ was considered significant. It was not possible to examine testretest reliability in this study, since the questionnaire was administered only once. Analyses were performed in IBM SPSS Statistics version 21.

\section{Results}

\section{Demographic characteristics}

Analyses were performed on 618 questionnaires of children and 590 questionnaires of parents (28 respondents $4.5 \%$ - did not complete all questions). Table 3 reports on the demographic characteristics for children and parents. ADHD had mainly been diagnosed by a psychiatrists or a pediatrician (67.8 and $17.8 \%$, respectively). Children were reported to be a responder to treatment in 428 cases $(69.3 \%)$ and non-responder to treatment in 190 cases $(30.7 \%)$. Mean age of children was 11.8 years. The number of comorbidities was similar between responder groups, although there was a near-significant difference of more children with three or more comorbidities in the nonresponder group compared to the responder group $(\mathrm{p}=$ 0.051). Comorbidities in the entire sample were Asthma or chronic Bronchitis ( $\mathrm{n}=78 ; 13 \%)$, Epilepsy ( $\mathrm{n}=7 ; 1 \%)$, Anxiety disorder $(n=80 ; 13 \%)$, mood disorder $(n=66$; $11 \%)$, learning disorder $(\mathrm{n}=235 ; 38 \%)$, Gilles de la Tourette/tic disorder $(n=25 ; 4 \%)$, ODD $/ C D(n=63$; $10 \%)$, mental retardation $(\mathrm{n}=4 ; 0.6 \%)$ and, Autism Spectrum Disorder (ASD) $(\mathrm{n}=152 ; 25 \%)$. Anxiety disorder (responder $\mathrm{n}=48-11.2 \%$, non-responder $\mathrm{n}=32-16.8 \%$; $\mathrm{p}=0.049$ ), and mood disorder (responder $\mathrm{n}=38-8.9 \%$, non-responder $\mathrm{n}=28-14.7 \%$; $\mathrm{p}=0.023)$ differed significantly between the responder and non-responder group with more cases in the responder group.

Data on resource use for children was missing for 19 respondents and data on resource use and production losses for parents for 27 respondents. This missing data was replaced by means of multiple imputation. Data were imputed based on the most optimal regression model. For children, this model was based on responder group (responder vs. non-responder), gender of the parent, $>1$ child with ADHD in the family and comorbidity. For parents, data was imputed based on a model with responder group, $>1$ child with ADHD, comorbidity and marital status.

Table 4 presents the mean and median monthly costs and their $95 \%$ confidence interval for direct medical and non-medical costs and indirect non-medical costs of children and parents. The group non-responding children incurred significantly higher total costs per month compared to responding children. This was reflected in total direct medical costs ( $€ 190$ higher), direct non-medical costs $(€ 74$ higher) and indirect non-medical costs $(€ 23$ higher). Day-care, trainings and doctor's consultation differed most remarkably between responder groups ( $€ 71, € 65$ and $€ 57$ higher for non-responders, respectively), with a significant difference for doctor's consultations (1.3 visits responding children vs. 2 visits non-responding children; $\mathrm{p}=0.004)$. Remedial teaching at school accounted for $€ 33$ extra per month for the non-responder group ( $€ 132$ for responders, $€ 165$ for non-responders; $\mathrm{p}=0.045$ ). For the questions on child's school absenteeism and failure to participate in sports no costs were assigned. Absence from sports due to ADHD was mentioned by the responder and the non-responder group (7.7 \% vs. $16.8 \%$ respectively, $\mathrm{p}=0.002)$. School absenteeism was reported for 72 days by the responder group and for 50 days by the non-responder group (16.8\% vs. $26.3 \%$ respectively, $\mathrm{p}=0.003)$. Estimated annual costs for responders and nonresponders to treatment were $€ 3864$ vs. $€ 6144$ for direct medical costs $(p=0.068)$, direct non-medical costs $€ 2664$ vs. $€ 3552(\mathrm{p}=0.090)$; indirect non-medical costs $€ 408$ vs. $€ 684(\mathrm{p}<0.001)$; and total costs for children $€ 6936$ vs. $€ 10,068, \mathrm{p}=0.021$ (responder vs. non-responder). Monthly costs per responder group are reported in Table 4.

For parents, total monthly costs were significantly different between responder groups, incurring higher costs of $€ 153$ for a parent when having a child non-responding to treatment. Estimated annual costs were $€ 2952$ for the parents of responding children and $€ 4788$ for parents of nonresponding children $(p=0.006)$. Both total direct medical and indirect non-medical monthly costs were higher for parents of a non-responding child with $€ 81 \quad(p=0.010)$ and $€ 65$ ( $p=0.092)$ respectively. As for children, doctor's consultations differed largely between responder groups and this difference was significant (responder 0.75 per month vs. non-responder 1.43 per month; $p=<0.001$ ). Estimated annual costs were $€ 1560$ vs. $€ 2532$ for direct medical costs $(p=0.010)$; indirect non-medical costs were $€ 1392$ vs. $€ 2172(p=0.092)$ and total costs were $€ 2952$ vs. $€ 4788$ ( $p=0.006$ ) (responder vs. non-responder).

Costs for children and parents combined led to a significant difference between responder groups in total costs with $€ 404$ extra per month when a child is a non- 
Table 3 Children's and parent's characteristics

\begin{tabular}{|c|c|c|c|c|}
\hline & Entire sample & Responder & Non-responder & $p$-value \\
\hline \multicolumn{5}{|l|}{ Children } \\
\hline $\mathrm{N}$ & $618(100.0 \%)$ & $428(69.3 \%)$ & 190 (30.7\%) & \\
\hline Mean age & $11.8(8-18)$ & $11.8(8-18)$ & $11.7(8-18)$ & 0.856 \\
\hline \multicolumn{5}{|l|}{ Gender } \\
\hline Male & $509(82.4 \%)$ & $359(83.9 \%)$ & $150(78.9 \%)$ & \multirow[t]{2}{*}{0.138} \\
\hline Female & $109(17.6 \%)$ & $69(16.1 \%)$ & $40(21.1 \%)$ & \\
\hline \multicolumn{5}{|c|}{ Number of comorbid disorders } \\
\hline 0 & $166(27.6 \%)$ & $126(30.0 \%)$ & $40(22.1 \%)$ & \multirow[t]{4}{*}{0.051} \\
\hline 1 & $242(40.3 \%)$ & $170(40.5 \%)$ & 72 (39.8 \%) & \\
\hline 2 & $132(22.0 \%)$ & $89(21.2 \%)$ & $43(23.8 \%)$ & \\
\hline 3 or more & $61(10.1 \%)$ & $35(8.3 \%)$ & $26(14.4 \%)$ & \\
\hline \multicolumn{5}{|l|}{ Type of education } \\
\hline Primary & $241(40.2 \%)$ & $165(39.3 \%)$ & 76 (42.2 \%) & \multirow[t]{4}{*}{0.119} \\
\hline Special primary & $86(14.3 \%)$ & $57(13.6 \%)$ & $29(16.1 \%)$ & \\
\hline Secondary & $219(36.5 \%)$ & $165(39.3 \%)$ & $54(30.0 \%)$ & \\
\hline Special secondary & $54(9.0 \%)$ & $33(7.9 \%)$ & $21(11.7 \%)$ & \\
\hline \multicolumn{5}{|l|}{ Parents } \\
\hline $\mathrm{N}$ & $590^{* *}(100.0 \%)$ & $415(70.3 \%)$ & $175(29.7 \%)$ & \\
\hline Age (mean, range) & $43.2(30-63)$ & $43.2(30-63)$ & $43.3(30-59)$ & 0.931 \\
\hline \multicolumn{5}{|l|}{ Gender } \\
\hline Male & $28(4.7 \%)$ & $22(5.3 \%)$ & $6(3.4 \%)$ & \multirow[t]{2}{*}{0.328} \\
\hline Female & $562(95.3 \%)$ & $393(94.7 \%)$ & $169(96.6 \%)$ & \\
\hline \multicolumn{5}{|l|}{ Marital status } \\
\hline Together & $534(90.5 \%)$ & $381(91.8 \%)$ & $153(87.4 \%)$ & \multirow[t]{2}{*}{0.097} \\
\hline Alone & $56(9.5 \%)$ & $34(8.2 \%)$ & $22(12.6 \%)$ & \\
\hline \multicolumn{5}{|l|}{ Education } \\
\hline Lower & $83(14.1 \%)$ & $59(14.2 \%)$ & $24(13.7 \%)$ & \multirow[t]{4}{*}{$* * *$} \\
\hline Medium & $265(44.9 \%)$ & $182(43.9 \%)$ & $83(47.4 \%)$ & \\
\hline Higher & $232(39.3 \%)$ & $166(40.0 \%)$ & $66(37.7 \%)$ & \\
\hline Other & $10(1.7 \%)$ & $8(1.9 \%)$ & $2(1.1 \%)$ & \\
\hline \multicolumn{5}{|l|}{ Paid job } \\
\hline Yes & $471(79.7 \%)$ & $328(79.0 \%)$ & $143(81.3 \%)$ & \multirow[t]{2}{*}{0.541} \\
\hline No & $120(20.3 \%)$ & $87(21.0 \%)$ & $33(18.8 \%)$ & \\
\hline \multicolumn{5}{|c|}{ More than 1 child with ADHD } \\
\hline Yes & $133(22.5 \%)$ & $85(20.5 \%)$ & $48(27.4 \%)$ & \multirow[t]{2}{*}{0.065} \\
\hline No & $457(77.5 \%)$ & $330(79.5 \%)$ & $127(72.6 \%)$ & \\
\hline
\end{tabular}

*p value reflects differences between responders and non-responders **28 parents did not complete the questionnaire

***Pearson Chi-Square not possible due to low expected numbers

responder to treatment (monthly costs responder $€ 824$, non-responder $€ 1228 ; \mathrm{p}=0.002$ ). Estimated annual costs were $€ 9888$ for the responder group and $€ 14,736$ for the non-responder group (difference $€ 4848 ; \mathrm{p}=0.002$ ). Multiple regression showed that the factors treatment response, gender of the parent, $>1$ child with ADHD and comorbidity had an independent influence on total costs for children. For total costs of parents, the factors treatment response, $>1$ child with ADHD, comorbidity and marital status of the parent were independent influencers. 
Table 4 Mean (median; $95 \%$ Cl) costs of children with ADHD and parents per month (in Euro 2012)

\begin{tabular}{|c|c|c|c|c|}
\hline & Entire sample & Responder & Non-responder & $p$-value \\
\hline \multicolumn{5}{|l|}{ Children } \\
\hline \multicolumn{5}{|l|}{ Direct Medical costs } \\
\hline Doctor's consultations ${ }^{* *}$ & $114(30)$ & $96(0 ; 78-115)$ & $153(95 ; 123-193)$ & 0.004 \\
\hline Trainings & 126 & $106(0 ; 69-148)$ & $171(0 ; 117-240)$ & 0.068 \\
\hline Day-care treatment & 73 & $51(0 ; 11-84)$ & $122(0 ; 32-218)$ & 0.144 \\
\hline Hospitalization & 41 & $41(0 ;-10-93)$ & $41(0 ;-37-125)$ & 0.999 \\
\hline Medication & $26(12)$ & $27(12 ; 25-30)$ & $24(12 ; 20-29)$ & 0.300 \\
\hline Diet & 5 & $4(0 ; 2-5)$ & $6(0 ; 4-10)$ & 0.145 \\
\hline Total direct medical costs & $386(109)$ & $326(96 ; 222-422)$ & $518(145 ; 334-691)$ & 0.068 \\
\hline \multicolumn{5}{|l|}{ Direct non-medical costs } \\
\hline Weekend care & 83 & $80(0 ; 59-104)$ & $91(0 ; 60-122)$ & 0.578 \\
\hline Remedial teaching at school & $142(110)$ & $132(0 ; 114-151)$ & 165 (110; 137-194) & 0.045 \\
\hline Care after-school & 6 & $6(0 ; 3-9)$ & $7(0 ; 2-12)$ & 0.638 \\
\hline Total direct non-medical costs & $232(110)$ & $218(110 ; 191-253)$ & $290(150 ; 224-315)$ & 0.090 \\
\hline \multicolumn{5}{|l|}{ Indirect non-medical costs } \\
\hline Agency for child welfare & 10 & $6(0 ; 3-9)$ & $20(0 ; 9-20)$ & $<0.001$ \\
\hline Police & 0 & $0(0 ; 0-0)$ & $1(0 ; 0-1)$ & 0.154 \\
\hline Special Education & $30(28)$ & $28(0 ; 23-33)$ & $36(0 ; 28-45)$ & 0.090 \\
\hline Total indirect non-medical costs & 41 & $34(0 ; 28-40)$ & $57(0 ; 46-68)$ & $<0.001$ \\
\hline Total costs children & $658(322)$ & $578(266 ; 465-691)$ & $839(511 ; 648-1029)$ & 0.021 \\
\hline \multicolumn{5}{|l|}{ Parents } \\
\hline \multicolumn{5}{|l|}{ Direct Medical costs } \\
\hline Doctor's consultations $s^{* * * *}$ & 60 & $47(0 ; 39-57)$ & $88(33 ; 69-108)$ & $<0.001$ \\
\hline Trainings & 93 & $81(0 ; 54-109)$ & $118(0 ; 74-166)$ & 0.145 \\
\hline Medication & 1.60 & $0.93(0 ; 0.5-1.3)$ & $3.1(0 ; 2-4)$ & $<0.001$ \\
\hline Total direct medical costs & 154 & $130(0 ; 98-162)$ & $211(82 ; 153-269)$ & 0.010 \\
\hline \multicolumn{5}{|l|}{ Indirect non-medical costs } \\
\hline Productivity losses due to absenteeism and presenteeism & 136 & $116(0 ; 74-159)$ & $181(0 ; 113-259)$ & 0.092 \\
\hline Total costs parents & $292(65)$ & $246(21 ; 191-300)$ & $399(182 ; 298-482)$ & 0.006 \\
\hline \multicolumn{5}{|l|}{ Children and parents together } \\
\hline Total costs & $948(524)$ & $824(412 ; 690-957)$ & $1228(740 ; 1003-1453)$ & 0.002 \\
\hline
\end{tabular}

* $p$ value reflects differences between responders and non-responders

**All consultations are summed up. Table 2 provides an overview specified per type of doctor

\section{Discussion}

The purpose of this study was to estimate ADHD related costs for children and their parents taking a societal perspective associated with treatment response. Nonresponse to treatment was shown to be associated with significant higher direct and indirect costs both inside and outside healthcare for children as well as their parents. Estimated annual costs differed between response groups, with extra costs of $€ 4848$ for non-responders. Costs for special education were very low relative to the other cost items in this study. This could reflect little need for extra attention, but it can also be a reflection of the general national Dutch trend towards less use of special education (Dekker 2015). A study on the economic impact of ADHD in Europe concluded that the largest cost category was in fact in education representing $50 \%$ of national costs on average (Le et al. 2013). The study did not include non-paid work based on the assumption that parents of children aged 8-18 would have limited voluntary activities. They could be coach of sports teams, be of help in their church or follow higher education. These costs were not included and could have impacted the absolute results. Most children were boys, which is consistent with other studies in ADHD. In the entire sample, only $28 \%$ had no comorbidity and $10 \%$ even had more than three 
comorbidities. This is consistent with the estimation that in general around $60-100 \%$ of patients with ADHD exhibit one or more comorbid disorders (Faber et al. 2010; Gillberg et al. 2004). The percentage of $10 \%$ of children with comorbid ODD/CD and $25 \%$ of ASD in our study group seems to be low compared to other studies (Gillberg et al. 2004; Erskine et al. 2014). Anxiety disorder and mood disorder differed significantly between the responder and non-responder group with more cases in the responder group. This outcome was not expected, since comorbidity is expected to negatively influence ADHD outcomes (Gillberg et al. 2004).

Recently, a systematic review was performed on European studies of ADHD-related costs published between 1990 and 2013 (Le et al. 2013). Only seven studies were found. The studies were conducted in Belgium, the Netherlands, Germany $(\mathrm{n}=3)$, Sweden and the United Kingdom. All studies included direct medical costs for children, but only one study included direct medical costs for family members whereas only two included costs of productivity loss of family members (indirect non-medical costs) (Hakkaart-van Roijen et al. 2007; Myren et al. 2010). Considering the methodology and the country of origin, only one study in the review can be compared well to the study at hand (Hakkaart-van Roijen et al. 2007). In that study, three groups were studied based on proxy reporting by the mother: 70 children treated by a pediatrician for ADHD, a non-matched group of 35 children with behavior problems and 60 children without behavior problems. The study showed the yearly direct medical costs of ADHD patients to be $€ 2040$. Moreover, ADHD children incurred yearly direct medical costs of $€ 5908$ which is in the range we found in our study ( $€ 3864$ for responders to $€ 6144$ for non-responders). Indirect costs for the mothers of children with ADHD were $€ 2243$ for mothers compared to $€ 1560$ in our responder group and $€ 2172$ in our non-responder group.

It has been described before that studying ADHD is a challenge and concessions must be made considering time, money and information needed (Arnold et al. 1997). Limitations of our study are the following. First of all, a practical choice had to be made regarding selection of participants. As an alternative, the possibility to include parents of children already participating in a trial related to ADHD was discussed. It was decided not to do so, because of burden for participants and potential bias. We chose for parents who are a member of an ADHD parent association. Because of this membership, it was assumed valid to rely on the parents' knowledge about the ADHD diagnosis of their child. Due to anonymity it was not possible to verify whether the diagnosis was valid or to collect data on disease severity. Similar considerations were stated in an earlier study, which used the same method of parent selection based on considerations of practicability, convenience and reliability (De Ridder \& De Graeve 2006). With respect to generalizability of this data, future studies should take the specific study group in this study into account. Second, other than the descriptions provided by parents, no insight in actual medication use by means of for example a saliva test was available. This has been shown to provide different results compared to parent report (Pappadopulos et al. 2009). Third, the definition of nonresponder in this study differs from clinical trials. These trials mainly aim at short-term effects and therefore at symptomatic improvement. This study aimed to focus on functional improvement as well. We explicitly broadened our definition of response and non-response, given our attempt to add to data generation on burden of illness in ADHD. Furthermore, it is questioned if current clinical trial designs in ADHD and response definitions are useful for measurement of individual treatment response anyway (Hodgkins et al. 2013). The definition we used provided a hands-on description of the study groups which provided easy reference to the respondents. Since we also wanted to ask questions on quality of life and costs for both the children and the parents we decided not to increase the questionnaire any further with a more in-depth description of functioning consisting of multiple questions. The statement of responders has been carefully assessed by the experts, but not by parents. We assumed the definition to be clear to parents, although the potential for alternative interpretations cannot be fully ruled out. Fourth, since we relied on a membership pool of an ADHD parent association, it could be the case that more severe ADHD cases were included in this study with a potential upward bias in the estimation of costs. Although, this is in conflict with the low percentage of comorbid ODD and ASD. Fifth, due to the cross-sectional methodology we cannot speculate about the causal relationship between these results and/or potential long-term benefits or disadvantages. A sixth point of interest in this study is that the definition of 'response to treatment' and 'non-response to treatment' includes some statement on impaired functioning of the non-responding child. One might postulate that impaired functioning a priori leads to higher costs. On the other hand, the response definitions did not include any statement on health care resource use which is the main focus of this study. Considering the remarkable difference in costs between both groups, the main conclusion of our study implying that non-response to treatment leads to higher costs seems to hold. We therefore assume the influence of this response definition to be modest only. Seventh, in case parents reported to have more than one child with ADHD, they were asked to report on their youngest child in order to reach consistency. The influence of this guidance is unknown. It could have resulted in underestimation of costs due to experience of the parent with the older child with ADHD, but also in overestimation 
since the youngest child was diagnosed most recently which could be associated with higher costs or younger children requiring more attention in general. Finally, next to pharmacological treatment, other types of treatment could have had an influence on the results since multimodal interventions are recommended for ADHD treatment (Daley et al. 2014; Trimbos-instituut et al. 2005). Pharmacological treatment together with interventions using behavioral techniques form the foundation for ADHD treatment (Trimbos-instituut et al. 2005). A metaanalysis of randomized controlled trials concluded that behavioral interventions have positive effects on a range of outcomes when used with patients with ADHD (Daley et al. 2014). Due to the method of our study it cannot be distinguished what the specific influence of either pharmacological treatment or behavioral interventions has been.

On the basis of our study, we would recommend future studies to use a random sample from multiple countries with possibilities to confirm diagnosis including validated checks on compliance, including validated questionnaires reporting on symptomatology (e.g. ADHD-RS-IV ADHD Rating Scale version 4 (Makransky \& Bilenberg 2014)) and functioning (e.g. CGI-I Clinical Global Impression scale) (Busner \& Targum 2007)), and existence of a control group using a longitudinal methodology with patient self-report, and parent and teacher report.

\section{Conclusions}

The results of this study provide relevant information for health care provision and use, since the results stress the importance of focusing on achieving response to treatment in children receiving (pharmacological) treatment for ADHD. Direct medical costs for children - specifically day-care treatment and trainings - were identified to be the most disparate with higher costs in the non-responder group. Direct non-medical costs were also unequal between groups with the highest difference in coaching at school. For parents of children with ADHD, doctor's consultations were higher in the responder group. Treatment pathways should incorporate a focus on achieving response to treatment reflected in recovery both at home and at school and proper compliance to prescription. Also family involvement should be a standard part of the pathway.

The results of this study contribute to the large evidence gap in societal cost calculation related to ADHD and emphasize the need for a broad perspective when analyzing problems related to ADHD since non-medical costs have a large contribution to total ADHD-related costs. With the trend of cost-effectiveness studies being used increasingly in guideline development and clinical decision-making, there is a clear need for comprehensive cost studies like the study at hand (Marsden \& Wonderling 2013). As was described by others, programs to facilitate collaboration among payers, patients, employers, and educational institutions may provide opportunities to create strategies to consider the societal impact of ADHD and strategies to mitigate its impact (Doshi et al. 2012). This study may aid in indicating which parts of healthcare consumption and non-direct and indirect costs such strategy should primarily be focused on.

\section{Abbreviations \\ ADHD: Attention deficit hyperactivity disorder; ASD: Autism spectrum disorder; C: Compliance; CD: Conduct disorder; Ch: Children; F: Functioning; LE: Linear extrapolation; ODD: Oppositional defiant disorder; P: Parents; RIAGG: Dutch mental health facility: a combination of 1st and 2nd line care; TiC-P: Questionnaire on healthcare consumption and productivity losses for patients with psychiatric disorders; QoL: Quality of life.}

\section{Competing interests}

$\mathrm{LH}, \mathrm{CB}$ and SS have no conflicts of interest. AK is a PhD Student at Radboud University and also an employee of Janssen-Cilag BV, but is not a shareholder of this company. MA is a former employee of Janssen-Cilag BV (until September 2014) and currently works for Gilead Sciences BV. JB has been in the past years a consultant to - member of advisory board of - and/or speaker for Janssen-Cilag, Eli Lilly, Bristol-Myers Squibb, Schering Plough, UCB, Shire, Novartis and Servier. He is not an employee of any of these companies, nor a stock shareholder. He has no other financial or material support, including expert testimony, patents, and royalties.

\section{Authors' contributions}

AK and MA came up with the idea of the study and have made substantial contributions to conception and design, acquisition of data, and analysis and interpretation of data. JB, LH and CB provided their input on the design of the questionnaire for this specific study. CB was involved in coordination of the study as she was the contact for parents that had any questions. AK and MA coordinated the roll out of the study and arranged the set-up of the online questionnaire and applied necessary policies for privacy of participants. $A K$ and MA performed the statistical analysis and prepared the first draft of the manuscript. JB, LH, CB and SS revised the manuscript critically for important intellectual content. LH, CB and SS supervised the study from a health technology assessment point of view, whereas JB supervised the study from a psychiatry point of view. All authors were involved in the interpretation of the data, and in review and approval of the manuscript. All authors read the final manuscript and have given approval of this version to be published.

\section{Acknowledgements}

We would like to thank Kathleen Provinciael and Baudowine Flipse working for Janssen-Cilag BV for their support in cooperating with Balans and acquisition of data by programming the questionnaire. The study was directly funded by Janssen-Cilag BV, Tilburg, the Netherlands since AK is an employee of this company and follows a PhD training in order to increase skills for her job. This funding relates to costs for data collection, publishing and time invested from AK and MA.

\section{Author details}

${ }^{1}$ Radboud University Medical Centre, Donders Institute for Brain, Cognition and Behavior, Department of Cognitive Neuroscience, P.O. Box 9010, 6500,

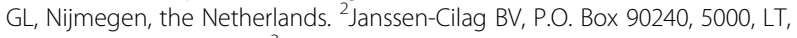
Tilburg, the Netherlands. ${ }^{3}$ Institute for Medical Technology Assessment (iMTA), P.O. Box 1738, 3000, DR, Rotterdam, the Netherlands. ${ }^{4}$ Karakter Child and Adolescent Psychiatry University Centre, Reinier Postlaan 12, 6525, GC, Nijmegen, the Netherlands. ${ }^{5}$ Gilead Sciences B.V., Amsterdam, The Netherlands.

Received: 11 February 2015 Accepted: 13 April 2015

Published online: 15 May 2015

\section{References}

Arnold LE, Abikoff HB, Cantwell DP, Conners CK, Elliott G, Greenhill LL, Hechtman L, Hinshaw SP, Hoza B, Jensen PS, Kraemer HC, March JS, Newcorn JH, Pelham WE, Richters JE, Schiller E, Severe JB, Swanson JM, Vereen D, Wells KC (1997) National 
institute of mental health collaborative multimodal treatment study of children with ADHD (the MTA): Design challenges and choices. Arch Gen Psychiatry 54:865-870

Asherson P (2004) Attention-deficit hyperactivity disorder in the post-genomic era. Eur Child Adolesc Psychiatry 13(Suppl 1):150-170

Banaschewski T, Coghill D, Santosh P, Zuddas A, Asherson P, Buitelaar J, Danckaerts M, Dopfner M, Faraone SV, Rothenberger A, Sergeant J, Steinhausen HC, Sonuga-Barke EJ, Taylor E (2006) Long-acting medications for the hyperkinetic disorders. A systematic review and European treatment guideline. Eur Child Adolesc Psychiatry 15:476-495

Barkley RA (2008) Global issues related to the impact of untreated attention-deficit/ hyperactivity disorder from childhood to young adulthood. Postgrad Med 120:48-59

Birnbaum HG, Kessler RC, Lowe SW, Secnik K, Greenberg PE, Leong SA, Swensen AR (2005) Costs of attention deficit-hyperactivity disorder (ADHD) in the US: excess costs of persons with ADHD and their family members in 2000. Curr Med Res Opin 21:195-206

Bouwmans CAM, Hakkaart-van Roijen L (2013a) Questionnaires for the measurement of costs in economic evaluations. TiC-P, Manual

Bouwmans CAM, Hakkaart-van Roijen L (2013b) TiC-P volwassenen. Vragenlijst over zorggebruik en productiviteitsverliezen bij psychische aandoeningen.

Bouwmans C, De Jong K, Timman R, Zijlstra-Vlasveld M, Feltz-Cornelis C, Tan SS, Hakkaart-van Roijen L (2013a) Feasibility, reliability and validity of a questionnaire on healthcare consumption and productivity loss in patients with a psychiatric disorder (TiC-P). BMC Health Serv Res 13:217

Bouwmans CAM, Schawo S, Hakkaart-van Roijen L (2013b) TiC-P voor kinderen.

Buitelaar JK, Van der Gaag RJ, Swaab-Barneveld H, Kuiper M (1995) Prediction of clinical response to methylphenidate in children with attention-deficit hyperactivity disorder. J Am Acad Child Adolesc Psychiatry 34:1025-1032

Busner J, Targum SD (2007) The clinical global impressions scale: applying a research tool in clinical practice. Psychiatry (Edgmont) 4:28-37

Canadian Attention Deficit Hyperactivity Disorder Resource Alliance (2010) Canadian ADHD Practice Guidelines third version

Charach A, Fernandez R (2013) Enhancing ADHD medication adherence: challenges and opportunities. Curr Psychiatry Rep 15:371

Coghill D, Soutullo C, d'Aubuisson C, Preuss U, Lindback T, Silverberg M, Buitelaar J (2008) Impact of attention-deficit/hyperactivity disorder on the patient and family: results from a European survey. Child AdolescPsychiatr Ment Health 2:31

College voor zorgverzekeringen afdeling pakket (2006) Richtlijnen voor farmacoeconomisch onderzoek, geactualiseerde versie

Daley D, Van der Oord S, Ferrin M, Danckaerts M, Doepfner M, Cortese S, Sonuga-Barke EJ (2014) Behavioral interventions in attention-deficit/hyperactivity disorder: a meta-analysis of randomized controlled trials across multiple outcome domains. J Am Acad Child Adolesc Psychiatry 53:835-847

Danckaerts M, Sonuga-Barke EJ, Banaschewski T, Buitelaar J, Dopfner M, Hollis C, Santosh P, Rothenberger A, Sergeant J, Steinhausen HC, Taylor E, Zuddas A, Coghill D (2009) The quality of life of children with attention deficit/hyperactivity disorder: a systematic review. Psychiatry, Eur Child Adolesc

Dekker S (2015) Zevende voortgangsrapportage passend onderwijs over de combinatie van onderwijs en zorg. Brief aan Tweede Kamer op 12 juni 2015. Referentie 770507

De Ridder A, De Graeve D (2006) Healthcare use, social burden and costs of children with and without ADHD in Flanders, Belgium. Clin Drug Investig 26:75-90

Doshi JA, Hodgkins P, Kahle J, Sikirica V, Cangelosi MJ, Setyawan J, Erder MH, Neumann PJ (2012) Economic impact of childhood and adult attentiondeficit/hyperactivity disorder in the United States. J Am Acad Child Adolesc Psychiatry 51:990-1002

Erskine HE, Ferrari AJ, Polanczyk GV, Moffitt TE, Murray CJ, Vos T, Whiteford HA, Scott JG (2014) The global burden of conduct disorder and attention-deficit/ hyperactivity disorder in 2010. J Child Psychol Psychiatry

Evans C, Crawford B (2000) Expert judgement in pharmacoeconomic studies. Guidance and future use Pharmacoeconomics 17:545-553

Faber A, Kalverdijk $L$, den Berg LT d J-v, Hugtenburg JG, Minderaa RB, Tobi H (2010) Co-morbidity and patterns of care in stimulant-treated children with ADHD in the Netherlands. Eur Child Adolesc Psychiatry 19:159-166

Faraone SV, Biederman J, Mick E (2006) The age-dependent decline of attention deficit hyperactivity disorder: a meta-analysis of follow-up studies. Psychol Med 36:159-165

Gillberg C, Gillberg IC, Rasmussen P, Kadesjo B, Soderstrom H, Rastam M, Johnson M, Rothenberger A, Niklasson L (2004) Co-existing disorders in ADHD - implications for diagnosis and intervention. Eur Child Adolesc Psychiatry 13(Suppl 1):180-192
Hakkaart-van Roijen L, Zwirs BW, Bouwmans C, Tan SS, Schulpen TW, Vlasveld L, Buitelaar JK (2007) Societal costs and quality of life of children suffering from attention deficient hyperactivity disorder (ADHD). Eur Child Adolesc Psychiatry 16:316-326

Hakkaart-van Roijen L, Tan SS, Bouwmans CAM (2011) Handleiding voor kostenonderzoek. Methoden en standaard kostprijzen voor economische evaluaties in de gezondheidszorg. Geactualiseerde versie 2010. In: Diemen (ed) College voor zorgverzekeringen (CVZ)

Hiligsmann M, Boonen A, Rabenda V, Reginster JY (2012) The importance of integrating medication adherence into pharmacoeconomic analyses: the example of osteoporosis. Expert Rev Pharmacoecon Outcomes Res 12:159-166

Hodgkins P, Dittmann RW, Sorooshian S, Banaschewski T (2013) Individual treatment response in attention-deficit/hyperactivity disorder: broadening perspectives and improving assessments. Expert Rev Neurother 13:425-433

Jonsson B (2009) Ten arguments for a societal perspective in the economic evaluation of medical innovations. Eur J Health Econ 10:357-359

Kengetallen SF (2012) Prognose geneesmiddelkosten over 10 jaar. Pharm Weekbl $147: 1-2$

Landelijke beroepsvereniging remedial teachers (2014) Tarieven remidial teaching., http://www.lbrt.nl/

Le HH, Hodgkins P, Postma MJ, Kahle J, Sikirica V, Setyawan J, Erder MH, Doshi JA (2013) Economic impact of childhood/adolescent ADHD in a European setting: the Netherlands as a reference case. Psychiatry, Eur Child Adolesc

Makransky G, Bilenberg N (2014) Psychometric properties of the parent and teacher ADHD Rating Scale (ADHD-RS): measurement invariance across gender, age, and informant. Assessment 21:694-705

Manca A, Palmer S (2005) Handling missing data in patient-level cost-effectiveness analysis alongside randomised clinical trials. Appl Health Econ Health Policy 4:65-75

Mannuzza S, Klein RG, Moulton JL III (2008) Lifetime criminality among boys with attention deficit hyperactivity disorder: a prospective follow-up study into adulthood using official arrest records. Psychiatry Res 160:237-246

Marsden G, Wonderling D (2013) Cost-effectiveness analysis: role and implications. Phlebology 28(Suppl 1):135-140

Michielsen M, Semeijn E, Comijs HC, van de Ven P, Beekman AT, Deeg DJ, Kooij J (2012) Prevalence of attention-deficit hyperactivity disorder in older adults in The Netherlands. Br J Psychiatry 201:298-305

Myren KJ, Thernlund G, Nylen A, Schacht A, Svanborg P (2010) Atomoxetine's effect on societal costs in Sweden. J Atten Disord 13:618-628

Osterhaus JT, Gutterman DL, Plachetka JR (1992) Healthcare resource and lost labour costs of migraine headache in the US. Pharmacoeconomics 2:67-76

Pappadopulos E, Jensen PS, Chait AR, Arnold LE, Swanson JM, Greenhill LL, Hechtman L, Chuang S, Wells KC, Pelham W, Cooper T, Elliott G, Newcorn JH (2009) Medication adherence in the MTA: saliva methylphenidate samples versus parent report and mediating effect of concomitant behavioral treatment. J Am Acad Child Adolesc Psychiatry 48:501-510

Polanczyk G, de Lima MS, Horta BL, Biederman J, Rohde LA (2007) The worldwide prevalence of ADHD: a systematic review and metaregression analysis. Am J Psychiatry 164:942-948

Shaw M, Hodgkins P, Caci H, Young S, Kahle J, Woods AG, Arnold LE (2012) A systematic review and analysis of long-term outcomes in attention deficit hyperactivity disorder: effects of treatment and non-treatment. BMC Med 10:99

Swanson JM, Wigal T, Lakes K (2009) DSM-V and the future diagnosis of attention-deficit/hyperactivity disorder. Curr Psychiatry Rep 11:399-406

Swensen AR, Birnbaum HG, Secnik K, Marynchenko M, Greenberg P, Claxton A (2003) Attention-deficit/hyperactivity disorder: increased costs for patients and their families. J Am Acad Child Adolesc Psychiatry 42:1415-1423

Thompson AL, Molina BS, Pelham W Jr, Gnagy EM (2007) Risky driving in adolescents and young adults with childhood ADHD. J Pediatr Psychol 32:745-759

Trimbos-instituut, Landelijke Stuurgroep Multidisciplinaire Richtlijnontwikkeling in de ggz, Werkgroep ADHD bij kinderen en jeugdigen (2005) Multidisciplinaire Richtlijn ADHD. Richtlijn voor de diagnostiek en behandeling van. ADHD bij kinderen en jeugdigen, Utrecht

van den Ban E, Souverein P, Meijer W, van Engeland H, Swaab H, Egberts T, Heerdink E (2014) Association between ADHD drug use and injuries among children and adolescents. Eur Child Adolesc Psychiatry 23:95-102

van Onderwijs CWM (2012) Kerncijfers 2007-2011. Onderwijs, Cultuur en Wetenschap National Institute for Health and Clinical Excellence (2006) Methylphenidate, atomoxetine and dexamfetamine for attention deficit hyperactivity disorder 
(ADHD) in children and adolescents. NICE, London, 2006 Mar [online]. http://www.nice.org.uk/TA098

Nederlandse Orde van Alternatieve Genezers (2013) Unit cost for alternative therapist., www.noag.org

Nibud (2013) Hoeveel betaalt u de oppas?., http://www.nibud.nl/uitgaven/ kinderen/oppas.html

van den Ban E, Souverein P, Swaab H, van EH, Heerdink R, Egberts T (2010) Trends in incidence and characteristics of children, adolescents, and adults initiating immediate-or extended-release methylphenidate or atomoxetine in the Netherlands during 2001-2006. J Child Adolesc Psychopharmacol 20:55-61

van der Kolk A, Bouwmans CAM, Schawo SJ, Buitelaar JK, van Agthoven M, Hakkaart-van Roijen $L$ (2014) Association between quality of life and treatment response in children with attention deficit hyperactivity disorder and their parents. J Ment Health Policy Econ 17:111-121

van Roijen L, Essink-Bot ML, Koopmanschap MA, Bonsel G, Rutten FF (1996) Labor and health status in economic evaluation of health care. The Health and Labor Questionnaire. Int J Technol Assess Health Care 12:405-415

Wolraich M, Brown L, Brown RT, DuPaul G, Earls M, Feldman HM, Ganiats TG, Kaplanek B, Meyer B, Perrin J, Pierce K, Reiff M, Stein MT, Visser S (2011)

ADHD: clinical practice guideline for the diagnosis, evaluation, and treatment of attention-deficit/hyperactivity disorder in children and adolescents. Pediatrics 128:1007-1022

\section{Submit your manuscript to a SpringerOpen ${ }^{\circ}$ journal and benefit from:}

- Convenient online submission

- Rigorous peer review

- Immediate publication on acceptance

- Open access: articles freely available online

- High visibility within the field

- Retaining the copyright to your article

Submit your next manuscript at $\gg$ springeropen.com 